\title{
EDUCAÇÃO E RESPONSABILIDADE EMPRESARIAL: "NOVAS" MODALIDADES DE ATUAÇÃO DA ESFERA PRIVADA NA OFERTA EDUCACIONAL
}

\author{
Maria Vieira Silva* \\ Silvana Aparecida de SouZA*
}

\begin{abstract}
RESUMO: A intensificação da simbiose entre as esferas pública e privada é coetânea das mutaçôes operadas em nível macrossocial, derivadas, sobretudo, dos processos de reforma do Estado e das mudanças no mundo do trabalho. Neste artigo colocaremos em relevo os arenosos terrenos do espaço público e a expansão da intervenção do setor privado. Recuperamos os discursos, políticas e práticas do empresariado para a educação escolar mediante os dispositivos da responsabilidade social empresarial e do trabalho voluntário. Evidencia-se que esses mecanismos estão em consonância com a lógica mercantil do capitalismo neoclássico mediante duas dimensões: a ambientação do (futuro) trabalhador aos processos de reestruturação produtiva e a naturalização da "solidariedade entre emprego e não-emprego", por meio do "trabalho voluntário" neste novo ciclo de produção da mais-valia.
\end{abstract}

Palavras-chave: Educação e trabalho. Público e privado. Escola e empresa.

EDUCATION AND CORPORATE RESPONSIBILITY:

THE “NEW" PRACTICE RULES OF THE PRIVATE SPHERE

IN EDUCATION PROVISION

ABSTRACT: The intensification of the symbiosis between public and private spheres coincides with changes at the macro-social

* Doutora em Educação e professora da Universidade Federal de Uberlândia (UFU). E-mail: mvs@ufu.br

* Doutora em Educação e professora da Universidade Estadual do Oeste do Paraná (UNIOESTE, Foz do Iguaçu). E-mail: souzasilvana@uol.com.br

Educ. Soc., Campinas, vol. 30, n. 108, p. 779-798, out. 2009

Disponível em <http://www.cedes.unicamp.br> 
Educação e responsabilidade empresarial: "novas" modalidades de atuação...

level, which essentially derive from the State reform processes and changes in the working world. This paper emphasizes the "sandy lands" of the public space and the expansion of the private sector intervention. It explored the speeches, policies and practices of entrepreneurship education for the school through the devices of corporate social responsibility and voluntary work. It shows that these mechanisms are consistent with the logic of the neo-classical market capitalism in two dimensions: the adaption of (future) workers to the processes of productive restructuring and the naturalization of the "solidarity between employment and unemployment" through "voluntary work" in this new cycle of production of added value.

Key words: Education and work. Public and private education. Education and business.

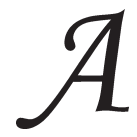

história da educação brasileira nos permite constatar que, nos mais variados contextos sociais, os propugnadores do desenvolvimento econômico buscaram na educação escolar uma aliada para satisfação de seus interesses. Assim, a ênfase na escola como instituição provedora da competência técnica do trabalhador, visando à produção de riquezas para o país, é recorrente em diferentes momentos históricos.

No início da década de 1960, a preocupação com a educação, como um fator de desenvolvimento nacional, torna-se candente no meio empresarial brasileiro. Souza (1981), na pesquisa intitulada "Os empresários e a educação - o IPES e a política educacional após 1964”, faz um levantamento de documentos no Arquivo Nacional e demonstra, por meio das fontes investigadas, que o Instituto de Pesquisas de Estudos Sociais (IPES) exerceu um importante papel na elaboração de políticas educacionais no quadro institucional do regime militar. O IPES foi fundado em 1961 por um grupo formado principalmente por empresários, profissionais liberais e elementos das forças armadas. O editorial do boletim Que é IPES? afirma que essa entidade oferece soluçóes para os problemas brasileiros, apontando todas as "reformas necessárias ao País, de repulsa à luta de classes e de pregação da harmonia social pela realização da justiça social” (apud Souza, 1981, p. 39-40). Souza recupera ainda o discurso de um dos membros, Glycon de Paiva, o qual explicita o ideário deste Instituto: "O IPES foi organizado com o objetivo 
de preservar a ordem capitalista e conduzir as reformas para a produtividade e a justiça social" (idem, ibid.).

$\mathrm{Na}$ concepção do IPES, a educação escolar teria um papel relevante para suprir as necessidades de desenvolvimento econômico e se constituiria também em importante fator de desenvolvimento social. Segundo as proposiçōes dos precursores das questóes educacionais do Instituto, como José Roberto Moreira, o desenvolvimento econômico do país é o parâmetro para a reestruturação educacional: “(...) o Brasil, apesar de atrasado culturalmente, é um país em franco desenvolvimento econômico e que, por isso, necessita de gente educada, qualquer que seja sua capacitação, em quase todos os setores de atividades" (apud Souza, 1981, p. 62).

Essas manifestações discursivas e institucionais, ainda que enfocadas sumariamente, permitem-nos apreender os diferentes mecanismos produzidos para sedimentar a relação entre o mundo do trabalho e o universo escolar, pautados na premissa do êxito da tríade entre educação escolar, desenvolvimento econômico e expansão do capital.

Maurício Tragtenberg, no início da década de 1980, ao desenvolver estudos sobre empresa como instituição sociopolítica - classificada por ele de estratégia de sedução -, identificou a perspectiva de "responsabilidade social" empresarial nos postulados dos ideólogos das grandes corporaçōes. Segundo o autor, Berle, por exemplo, "acredita firmemente nas 'harmonias econômicas', na identidade de interesses entre a sociedade e a grande corporação, desenvolvendo daí o conceito de empresa-comunitária" (Tragtenberg, 1980, p. 12). Nesta direção, assegura que "a corporação é reflexo de valores e atitudes que se desenvolveram inusitadamente, permitindo 'o salto da fase do barão assaltante para a empresa com responsabilidade social" (idem, ibid.). Tragtenberg afirma ainda que, de acordo com seus precursores, a gerência da grande corporação não se limita à procura da reles produtividade. Além de ser uma instituição, a corporação "é uma empresa com alma" (p. 13). Assim, defende que, embora a corporação vise à maximização de seus lucros - e, de fato, maximiza-os com projetos a longo prazo -, ela é uma obra de organização social e "isso permite a ela assumir o mecenato artístico e a filantropia social" (p. 16). Todavia, o autor conclui que, "na realidade, na medida em que a corporação é capitalista, somente poderá ser anti-social e privatista" (p. 17). 
Educação e responsabilidade empresarial: "novas" modalidades de atuação...

No contexto atual, o que pensam os empresários quando preconizam a escola como uma das propulsoras do desenvolvimento econômico? Quais suas percepçôes e proposiçôes acerca da relação entre o setor empresarial e a educação escolar? Neste artigo enfocaremos aspectos relacionados às novas modalidades da relação entre empresa e escola, expressos nos discursos empresariais produzidos nas últimas duas décadas e na materialização do ethos empresarial, por meio das ações de responsabilidade social e do voluntariado empresarial.

Os discursos empresariais produzidos na década de $1990^{1}$ evidenciam a perspectiva "anti-social" afirmada por Tragtenberg (1980), ao propor a educação escolar como condição para garantir o desenvolvimento das habilidades requeridas do trabalhador pelo novo conteúdo do trabalho, visando à maximização dos lucros no contexto da reestruturação produtiva.

Sob tal perspectiva, o Instituto de Estudos de Desenvolvimento Industrial (IEDI) produziu um documento intitulado "A nova relação entre competitividade e educação: estratégias empresariais", que ressalta, dentre outras questốes, que os mecanismos de seleção da mão-de-obra são atributos adquiridos por meio dos conteúdos de educação básica.

Esses pressupostos são reiterados por Silva Filho, coordenador de projetos na área educacional do Instituto Herbert Levy (IHL), da Gazeta Mercantil. Segundo ele, para se integrar no contexto atual e exercer eficazmente um papel na área econômica,

(...) o indivíduo tem que no mínimo saber ler, interpretar a realidade, expressar-se adequadamente, lidar com conceitos científicos e matemáticos abstratos, trabalhar em grupos na resolução de problemas relativamente complexos, entender e usufruir das potencialidades tecnológicas do mundo que nos cerca. E, principalmente, precisa aprender a aprender, condição indispensável para poder alcançar as mudanças e avanços cada vez mais rápidos que caracterizam o ritmo da sociedade moderna. (1996, p. 88)

Segundo o documento, não é intenção ou "missão" do Instituto substituir as ações do governo para o ensino público, mas assegura que a participação direta do empresário no trato das questóes educacionais é importante por três razões: "familiariza o empresário com a educação básica; porque no estado atual da educação brasileira é útil complementar a ação do governo; e porque é a empresa que mais ganha quando a 
comunidade onde se insere melhora seu padrão educacional" (idem, ibid.). O documento sugere ainda que, "além da participação direta, o empresário pode atuar localmente, participando da gestão da escola, e, através das confederações, que têm acesso ao poder, propor e cobrar políticas educacionais" (idem, ibid.).

Para a viabilização dessa participação, o IHL propôs, no início dos anos de 1990, que os empresários conhecessem o "ensino fundamental" e, com esse objetivo, elaborou, juntamente com a Fundação BRADESCO, o trabalho "Ensino fundamental e competitividade empresarial - uma proposta para ação do governo". O referido documento apresenta estratégias para mudanças da educação, mediante a implantação de instrumentos que assegurem o padrão mínimo de recursos para as escolas e mecanismos para a viabilização do sistema nacional de avaliação das mesmas:

No mundo dos negócios, cada vez que um produto fica pronto, toda empresa séria verifica se aquele produto corresponde às especificações que deve ter para ser entregue aos consumidores. Controlar a qualidade de tudo que é produzido é uma atividade de rotina. É natural que, em algo tão importante quanto à educação, os empresários esperem que o governo proceda da mesma forma, ou seja: que antes de entregar os alunos à sociedade, verifique se aprenderam o que precisam saber, de acordo com as especificaçóes estabelecidas pelo governo para cada nível de ensino. Trata-se da mesma idéia de controle da qualidade. (Instituto Herbert Levy, 1992, p. 47)

A Confederação Nacional das Indústrias (CNI) também apresentou proposiçôes do segmento empresarial para a escola básica no documento "Competitividade: proposta dos empresários para a melhoria da qualidade da educação" (1996). O documento dirige-se aos diferentes segmentos, propondo ações destinadas à educação básica, à educação profissional, ao ensino superior, à capacitação e requalificação de adultos e à gestão e tecnologia. Para cada nível supracitado, há especificaçóes que dizem respeito ao "âmbito estrutural", dirigidas aos governos federal, estaduais e municipais; ao "âmbito setorial", envolvendo a cooperação e a parceria entre empresas, entidades empresariais, instituições de ensino públicas e privadas e órgãos de governo; e ao "âmbito de cada empresa".

A educação do (futuro) trabalhador assume, pois, uma dimensão redentora, à medida que se torna requisito fundamental para o ingresso do Brasil no mercado competitivo da economia global. Dessa crença decorrem múltiplos desdobramentos para sua operacionalização, 
Educação e responsabilidade empresarial: "novas" modalidades de atuação...

influenciando várias políticas e proposições para o setor. Provocar uma ruptura com o sedutor discurso de segmentos da sociedade que professam a educação como a propulsora do desenvolvimento econômico e social dos países ditos periféricos e a colocam como prioridade, em termos quantitativos e qualitativos, nas ações da esfera governamental e empresarial, não é tarefa fácil. O desafio se instaura, sobretudo, por ser esta, historicamente, uma das principais reivindicações dos movimentos sociais, partidos políticos e sindicatos que se contrapõem à ordem social vigente.

No entanto, um olhar atento, voltado para as ações, diretrizes e para os sentidos menos objetivistas presentes nas relações complementares entre o setor empresarial e o governamental, evidencia que o nexo proposto para a educação e os sistemas produtivos, em prol do crescimento econômico, já foi utilizado como estratégia do capital em outras conjunturas, não havendo, em seus princípios básicos, qualquer novidade.

As novidades que tais mecanismos apresentam estão muito mais na forma do que no conteúdo, ou, conforme Foucault (1998, p. 26), “o novo não está no que é dito, mas no acontecimento de sua volta”. A investida do setor empresarial, e sua atuação, no interior da escola pública, diante da amplitude que esse movimento assume no contexto atual, não têm precedentes na historiografia da educação no Brasil. A seção que se segue propõe-se a problematizar alguns elementos ideológicos da investida do setor empresarial na escola pública.

Parcerias entre empresa e escola: novos vínculos sob antigos paradigmas

Os fragmentos dos discursos empresariais, apresentados na seção anterior, evidenciam que a participação do empresariado na gestão da escola pública não está provida apenas de um cariz técnico e operacional para garantir sua eficiência e produtividade, tampouco está movida por ações filantrópicas ou "socialmente responsáveis". Tal participação está ancorada por um forte conteúdo ideológico que opera na esfera cultural e política com alguns desdobramentos sobre o "currículo oculto" da escola. Apple, ao trabalhar com esta categoria, enfocou-a como os tipos de recursos e símbolos culturais, selecionados e organizados 
pelas escolas, que estão "dialeticamente relacionados com os tipos de consciência normativa e conceitual 'exigidos' por uma sociedade estratificada" (1982, p. 10). Assim, as escolas produzem e reproduzem formas de consciência que permitem a "manutenção do controle social sem que os grupos dominantes tenham de recorrer a mecanismos declarados de dominação" (p. 12). Outra noção que está presente na corporificação das relações entre escola e empresa, em sua dimensão cultural, é a noção de habitus. Segundo Bourdieu (1990), habitus é uma estrutura internalizada, são os valores e as formas de percepções dominantes incorporados pelo indivíduo e por meio dos quais ele percebe o mundo social. Para o autor (p. 158), "as representaçôes dos agentes variam segundo sua posição (e os interesses que estão associados a ela) e segundo seu habitus como sistema de esquemas de percepçôes a apreciação, como estruturas cognitivas e avaliatórias que eles adquirem através da experiência durável de uma posição do mundo social (...)”.

O habitus empresarial veiculado na escola busca a produção e reafirmação/consolidação de práticas visando à regulação comportamental e cultural dos estudantes, de forma a habituá-los à lógica hegemônica. Há nos princípios, condutas, normas, regras, rituais e procedimentos da empresa uma nova pedagogia da habituação, visando à conformação e à adequação dos estudantes à nova fase de produção da mais-valia. Segundo Silva (2001), a expressão pedagogia da habituação foi criada no sentido de traduzir o conjunto de dispositivos que visa à produção de novas subjetividades para os estudantes. Este conceito se traduz também pela reafirmação e consolidação de práticas, as quais visam à regulação comportamental e cultural de forma a habituá-los à lógica hegemônica do capital neste novo período de acumulação. Assim, a pedagogia da habituação conserva ou produz múltiplas relaçóes de poder por meio de princípios, condutas, normas, regras, rituais, os quais objetivam a conformação e adequação dos estudantes à nova fase da reestruturação produtiva (Silva, 2001). O que está presente no interior desta dinâmica é o estabelecimento das conexôes entre a dinâmica escolar e a dinâmica empresarial, provocando um ajustamento da escola ao universo mercantil segundo os desígnios do capital.

A partir de pesquisa empírica realizada sobre parcerias entre empresa e escola, desenvolvida em um município mineiro, Silva (op.cit.) assegura que a dimensão ideológica do currículo oculto incide por meio 
Educação e responsabilidade empresarial: "novas" modalidades de atuação...

de múltiplos aspectos, quais sejam: a conformação da organização do trabalho pedagógico ao reordenamento político e econômico do mundo do trabalho, mediante a veiculação dos aparatos culturais da lógica empresarial; a formação do trabalhador economicamente desejável, segundo os desígnios do pensamento empresarial expressos no currículo formal e oculto da escola; a ocupação de forma sistematizada da escola pública pelo setor produtivo privado; a simbiose entre a educação escolar e o mercado de trabalho numa perspectiva pragmática e a garantia da legitimidade da empresa no plano subjetivo, mas com resultados objetivos em seu processo de acumulação.

Depreende-se, pois, que a organização do trabalho na escola não é composta apenas por um conjunto de conteúdos escolares, que articulam em torno do currículo a produção das ciências e dos saberes construídos de forma neutra e apolítica. Simultaneamente à transmissão dos saberes científicos em forma de conteúdos programáticos organizados pelo currículo escolar, veiculam-se valores, imagens, hábitos, representações, normas de conduta, gestos e maneiras prescritos por uma cultura hegemônica.

Ainda segundo Silva (2001), a atuação empresarial na dinâmica escolar legitima conhecimentos, saberes e cultura empresarial, incorporados às narrativas do currículo escolar em que ora ocorre de forma mais manifesta, ora de forma mais implícita, ou oculta, por meio de pelo menos quatro dispositivos: a meritocracia como fator determinante de inclusão e exclusão; a disciplinarização como perspectiva de subsunção às exigências de produtividade; a premiação como propulsora do progresso pessoal e da regulação moral.

Os "conteúdos" da lógica empresarial são veiculados por meio de codificações presentes nas ações da empresa na escola. Estes preconizam a retenção dos princípios que sustentam a hegemonia do capital, por meio da maximização da produtividade dos mais "capazes" ou dos mais "aptos", dos dispositivos da disciplinarização e, ainda, pela dimensão meritocrática. Ao focalizar a relação entre o setor empresarial e a educação escolar, depreende-se sua vinculação com os mecanismos que se processam na prática social mais ampla, no aparelho de Estado. Para uma percepção mais acirrada do grau do poder das organizaçóes empresariais no capitalismo contemporâneo, é pertinente recorrer às formulações feitas por Bernardo (1998). O autor distingue duas configurações do Estado: Estado restrito e Estado amplo. $\mathrm{Na}$ sua concepção, o 
Estado restrito imprime as clássicas funções designadas pelos poderes Legislativo, Executivo e Judiciário e tem seu campo de ação demarcado no processo particularizado da economia. Assim, o Estado restrito assumiu um relevante papel articulador em contextos nos quais as unidades econômicas se encontravam em processo de particularização e isolamento recíproco. Nesta direção, as atribuições deste Estado ascendem e se legitimam quanto maior for a fragmentação do funcionamento das unidades econômicas. Quanto ao Estado amplo, a terminologia criada por Bernardo é por si só elucidativa da abrangência do seu conceito, pois, em sua definição, este Estado é constituído pelos mais variados mecanismos de produção da mais-valia das condiçôes gerais de produção. Nesta direção, as empresas compõem e são componentes do Estado amplo, uma vez que é no seu interior que são produzidos os princípios de administração da produção capitalista, a gestão da força de trabalho e a lógica de produção de mercadorias.

Destarte, o que caracteriza o declínio do Estado restrito e a ascensão do Estado amplo é a transnacionalização da economia. A partir do desenvolvimento e articulação das unidades econômicas e das condiçôes gerais de produção, há um arrefecimento do Estado restrito e ascensão do Estado amplo. Bernardo (1998) afirma que as companhias transnacionais são as principais responsáveis pelo processo de desagregação do Estado restrito e configuram-se como o elemento mais importante no interior do Estado amplo, pois elas

(...) têm a capacidade de prosseguir uma estratégia própria, independente dos governos tanto dos países onde estão implantadas as matrizes como daqueles onde se estabelecem as filiais. Elas não são um agente de um ou de outro governo estrangeiro, como pensam aqueles que ainda hoje raciocinam em termos estritamente nacionais. As companhias transnacionais são elas mesmas um poder, o mais importante na época atual. (p. 46)

Sob tal ótica, o processo de declínio do Estado restrito e ascensão do Estado amplo constitui um dos elementos determinantes na nova organização do mundo do trabalho que surge sob a mundialização do capital. Na esfera da política, instaura-se uma nova subjetividade para o trabalhador, por meio de mecanismos que provocam rupturas ou declínios na perspectiva da identidade de classe pela absorção da lógica do capital. São múltiplos e complexos os mecanismos utilizados 
Educação e responsabilidade empresarial: "novas" modalidades de atuação...

para a materialização, o desenvolvimento e a expansão do conteúdo ideológico do Estado amplo; um deles tem sido a instituição escolar. Essa instituição, sobretudo no atual momento de transnacionalização da economia, torna-se uma aliada fundamental para a personificação do poder deste Estado. Por outro lado, a própria intervenção do setor empresarial na gestão da escola, e em distintos espaços sociais, já é um demonstrativo do poder do Estado amplo que, de forma crescente, ganha espaços na esfera pública. Embora esses processos assumam diferentes e múltiplas feições na realidade brasileira, podemos localizar de forma expressiva a proposta de reforma do Estado formulada e implementada em meados da década de 1990. Quem são os "novos" partícipes do aparelho do Estado preconizado pela reforma? Como se estreitam os vínculos entre o setor público e privado?

Os pressupostos da reforma do Estado preconizados por Bresser Pereira (apud Brasil, 1995, p. 67) constituem-se em um marco referencial significativo no processo de institucionalização dos formatos da composição das esferas pública e privada, ao desenvolver a noção de publicização. Tal proposta se materializa por meio da "descentralização para o setor público não-estatal da execução de serviços que não envolvem o exercício do poder de Estado, mas devem ser subsidiados pelo Estado, como é o caso dos serviços de educação, saúde, cultura e pesquisa científica" (idem, ibid.). O Plano Diretor da Reforma do Estado, preconizado por Bresser Pereira, contribuiu para intensificar os mecanismos da transferência das atividades do poder público estatal para o setor privado.

Acirra-se assim a lógica dos "quase-mercados", que põem em evidência o caráter híbrido das novas formas de financiamento, fornecimento e regulação que o próprio Estado incentiva e que se inscreve na redefinição das suas funções, "promovendo, no interior de seu espaço estrutural, pressões competitivas entre serviços, adotando instrumentos e princípios de gestão baseados na racionalidade instrumental e subordinando os direitos sociais às lógicas da eficácia e da eficiência" (Afonso, 2003, p. 39). A conformação da educação escolar a esse novo ciclo do capitalismo contemporâneo tem contribuído de forma significativa para a proliferação de políticas e práticas educacionais, tendo como referenciais paradigmas advindos do neoliberalismo, mediante a "responsabilidade social empresarial" e o trabalho voluntário. 
O trabalho voluntário no contexto atual da sociedade capitalista: solidariedade entre emprego e não-emprego

O movimento de valorização e fortalecimento do conceito de Responsabilidade Social da Empresa (RSE) passa a ocorrer, sobretudo na última década, como mais uma das incontáveis estratégias de reorganização permanente do capital, para superar ou atenuar os sintomas das crises que fazem parte de seu "sociometabolismo" (Mészáros, 2002).

Nesse contexto, as açóes de RSE passaram a fazer parte do cotidiano empresarial e consistem, basicamente, em açōes de empresas no desenvolvimento de alguma atividade considerada de interesse público e que podem ser executadas nas mais diversas modalidades: seja na forma de repasse de recurso financeiro para entidades já existentes; seja na forma de criação de entidades sem fins lucrativos para desenvolver atividades determinadas ou atender a grupos sociais específicos; seja pelo estímulo a que seus funcionários e demais pessoas da comunidade atuem voluntariamente a favor de uma causa social. Por vezes, combinam-se todas essas modalidades ou apenas uma ou outra.

As ações de RSE se afirmam no argumento de que as empresas que as realizam buscam a cidadania e a sustentabilidade social e que não pretendem manter uma relação de assistencialismo com os grupos sociais atendidos. Por isso, as empresas preferem a área da educação para desenvolver seus programas de responsabilidade social, já que, se o movimento é de negação do assistencialismo, não seria coerente manter atividades de distribuição de alimentos, roupas ou remédios.

Mas o interesse proeminente no desenvolvimento das açóes de RSE na área da educação tem ainda outras explicaçōes. A esse respeito, Nathalie Beghin, apoiada em Eli Diniz e Renato Boschi, demonstra que a importância outorgada pelas lideranças empresariais à educação decorre do fato de a mesma ser considerada essencial para o aumento da competitividade econômica nacional e para a melhoria das condiçôes de inserção do país na nova ordem mundial (Beghin, 2005).

Assim, pode-se inferir que, por razões econômicas e pelo fato de carregar uma forte aceitação da população como uma ação que produz melhoria na vida das pessoas, a educação tem sido a área eleita pela maioria dos dirigentes de empresas para desenvolver açôes de responsabilidade social. 
Educação e responsabilidade empresarial: "novas" modalidades de atuação...

Além disso, o desenvolvimento das ações de RSE está relacionado com a possibilidade de aumento de lucros das empresas. Parece-nos bastante ilustrativa a afirmação de Percival Caropreso, presidente da McCann Erickson Social/Marketing, nova unidade da maior empresa de propaganda do mundo, que cuida exclusivamente de marketing social: "tornar a ação social mais eficiente não tem o objetivo de aumentar a milhagem das empresas em algum programa celeste, mas sim aumentar o próprio valor de suas marcas e seus lucros" (apud Lessa, 2002, p. 22).

David Grayson e Adrian Hodges explicitam as mudanças ocorridas atualmente no mundo que levam a uma alteração de postura na gestão empresarial:

O maior ímpeto para a mudança das práticas empresariais não se encontra no crescente sentido de responsabilidade social, mas nas forças do mercado - clientes interessados, funcionários com voz ativa e investidores pragmáticos preocupados com o valor do seu patrimônio. O que já foi apenas bom fazer deve hoje ser obrigatório. (Grayson \& Hodges, 2002, p. 7)

Nesse mesmo sentido, outro autor enfatiza que é papel da empresa adotar novas práticas gerenciais que privilegiem não apenas o êxito dos negócios, mas também os aspectos social, ambiental e humano, "senão por convicção, certamente por sobrevivência" (McIntoch, 2001, p. VII).

Ocorre que, no processo permanente de busca do aumento de lucros, ao tentar extrair o mais possível a mais-valia absoluta e a maisvalia relativa da força de trabalho contratada, o capitalista individualmente consegue uma mais-valia extra, que é temporária. Ela se efetiva quando, no processo de procura do aumento da produtividade, se descobre uma nova forma de produzir uma dada mercadoria com menor custo ou com maior produtividade. Decorre que, até que esse novo modo de produção se generalize à escala social, aqueles que a utilizam individualmente conseguem um lucro extra, que não acompanha, portanto, o padrão e a normalidade da produção. Pelo contrário, isso só é possível enquanto se mantiver na condição de diferencial de um processo de produção para outro, até que não seja apropriado pela concorrência. Ou, nos termos de Marx (1996, p. 366), "mas essa mais valia extra se desvanece quando se generaliza o novo modo de produção". 
Em função dessa mais-valia extra, o capitalista é impelido a sempre buscar o aperfeiçoamento das condições de produção e de circulação, que pode ocorrer na forma de melhoria dos processos de produção (o que se converte na redução de custos), ou das condições de circulação mediante a concorrência, como é o caso das ações de RSE. Mas parece importante ressaltar que isso se converte em vantagem para o capitalista somente enquanto essa nova forma de produção e/ou circulação não for adotada de modo generalizado pelo conjunto das organizaçôes concorrentes em cada ramo de produção.

Então, quando a maioria das empresas, em cada segmento, tiver adotado a prática do desenvolvimento de ações de RSE, isso deixará de ser um diferencial de uma ou algumas empresas e a vantagem obtida em função dessas ações irá se reduzir até sua extinção, iniciando-se o processo de busca de um novo diferencial.

Portanto, longe de acharmos que existe um maniqueísmo na mudança de atitude do empresariado hoje, ao se interessar pelo desenvolvimento de ações de RSE, instrumentalizando o trabalho voluntário de seus funcionários como uma vantagem mediante a concorrência, o que estamos afirmando é que o próprio empresário é, em certa medida, determinado pelas condições históricas de desenvolvimento do capitalismo. Se ele (o empresário) não acompanhar o movimento da realidade, que se traduz nas tendências de mercado, estará induzindo sua empresa ao fracasso em seus objetivos, que é a acumulação.

Sendo assim, o desenvolvimento de ações sociais não ocorre por serem elas um valor em si para a empresa, mas por se constituírem em uma nova exigência do mercado, assim como uma nova vantagem no mercado.

Entre as vantagens para a empresa que os defensores da RSE alegam, uma delas diz respeito aos funcionários, que melhoram seu desempenho e respectiva produtividade e desenvolvem ainda novas habilidades de liderança e trabalho em equipe, conforme demonstram Perez e Junqueira (2002). Outra vantagem é o aumento do sentido de pertencimento dos funcionários com relação à empresa. Isso também aumenta a satisfação no trabalho, fator que eleva a produtividade dos funcionários, que passam a defender a empresa, dissimulando em certa medida a polaridade entre capital e trabalho. Os mesmos autores têm ainda mais argumentos acerca das vantagens relacionadas às açóes de responsabilidade social desenvolvidas pela empresa: 
Educação e responsabilidade empresarial: "novas" modalidades de atuação...

Há relatos de empresas que registraram aumento na produtividade de seus funcionários após a implantação do voluntariado. (...) Os consumidores em condições iguais de preço e qualidade preferem adquirir produtos de empresas que praticam a solidariedade e que buscam a melhoria da sociedade por meio da melhoria das pessoas. A responsabilidade social é valorizada pelos consumidores. $\mathrm{O}$ governo muitas vezes declara sua satisfação de maneira pública com as ações sociais de muitas empresas, o que também colabora de maneira positiva para a construção de uma imagem favorável. (Perez \& Junqueira, 2002, p. 258)

Em uma perspectiva crítica à RSE, Eugênio Bucci denomina essa "nova 'solucionática' voluntária" de "solidariedade de mercado", a qual, segundo o autor, é necessariamente uma solidariedade exibicionista (2004, p. 182).

As ações de RSE necessitam de visibilidade para se reverter em benefício para a própria empresa, sob pena de perderem sua validade. Assim, a aparência pode bastar se o que se pretende é uma ação que se converta em uma imagem de empresa socialmente responsável, tornando-a mais competitiva, trazendo como consequência o aumento dos lucros. Ou seja, as ações de RSE não se baseiam na virtude em si, mas na sua aparência de virtude.

Ao adjetivar a "solidariedade de mercado", Bucci está precisamente destacando o caráter de aparência que essa solidariedade assume em sua atual configuração. Nos termos marxianos, um caráter de fetiche, tratando-se então da reificação do trabalho voluntário, da coisificação de uma relação social que assume agora a forma "mercadoria". O trabalho voluntário passa de valor social para valor de mercado e para o mercado. Por isso, as empresas têm demonstrado um interesse crescente em buscar funcionários que desenvolvam atividades sociais de forma voluntária. Nesse sentido, ao tratar do perfil, em termos de características pessoais que um voluntário necessita ter para desenvolver um trabalho social, Maria da Conceição Castro afirma:

O setor privado, por exemplo, tem buscado "caçar" talentos com esse perfil, no sentido de agregar valores às outras competências tradicionalmente requeridas, tarefa que não tem sido das mais fáceis, visto que isso depende menos de habilidades e competências adquiridas pelos profissionais, por meio de cursos e treinamentos, e muito mais de atitude. Esta é uma condição que envolve dimensões de valor que 
extrapolam as relaçốes puramente de troca entre patrão e empregado. (Castro, 2002, p. 74)

Porém, além de incentivar o desenvolvimento do trabalho voluntário por seus funcionários, existe também uma antecipação da empresa, exigindo que o possível candidato a uma vaga demonstre que já desenvolve atividades de cunho social. A detecção do desenvolvimento ou não dessas atividades ocorre no processo de recrutamento.

O desenvolvimento de uma atividade social, por meio do trabalho voluntário, torna-se então condição a ser assumida também para os que ainda não estão empregados, mas têm a perspectiva de se inserir ou se reinserir no mercado de trabalho:

A intensa valorização que as empresas brasileiras vêm dando ao trabalho voluntário, até como um item positivo nos currículos dos profissionais que se candidatam a cargos em seus quadros, tem contribuído para modificar o perfil do voluntariado brasileiro. Essa prática, já antiga no mercado de trabalho norte-americano, tem se difundido rapidamente entre as empresas brasileiras. (Perez \& Junqueira, 2002, p. 174)

As empresas de recrutamento de pessoal, sobretudo de executivos, têm orientado que, no curriculum vitae de um profissional apto à empregabilidade, não pode faltar a menção ao desenvolvimento de uma atividade voluntária de interesse social. A palavra "empregabilidade" ainda não consta dos dicionários brasileiros, mas já é usual no meio empresarial. Segundo José Augusto Minarelli, o termo equivalente em inglês é "employability: a condição de dar emprego ao que se sabe, a habilidade de ter emprego" (Minarelli, 1995, p. 37). Ao tratar da origem do conceito, o autor esclarece:

Para se ajustar às exigências da economia global, as organizações modificam-se com rapidez e não podem mais garantir o emprego até o profissional aposentar-se, como acontecia antigamente. São, aliás, cada vez mais raras as carreiras feitas em uma só empresa. Resultado: os empregadores começam a adotar uma política de preparar os seus funcionários para que estejam em condições de ter trabalho quando deixarem a organização. (Idem, ibid., p. 38)

Considerando tais explicações, pode-se depreender que empregabilidade tem sido considerada a qualidade de estar apto ao emprego. São as condições a que o trabalhador deve atender, objetivando 
Educação e responsabilidade empresarial: "novas" modalidades de atuação...

a possibilidade de conseguir emprego, considerando sua capacidade de enquadrar-se num perfil determinado pelas demandas do "mercado" de trabalho; e, para enquadrar-se no perfil da empregabilidade, atualmente, é condição que se desenvolva uma atividade social voluntária.

A análise até aqui empreendida leva à percepção de um movimento de solidariedade induzida, governada, entre emprego e não-emprego, no atual momento da sociedade capitalista. Note-se que não estamos tratando aqui da idéia de que todos trabalhem menos, propiciando que todos possam trabalhar e viver: isso seria impossível sem tocar na distribuição da riqueza produzida pela humanidade.

O significado que este estudo empreende à expressão "movimento de solidariedade (induzida, governada) entre emprego e não-emprego" está estreitamente vinculado às atuais configuraçōes do mundo do trabalho, demonstrando que tal solidariedade deve partir da atividade voluntária de quem tem ou pretende ter emprego para quem não mais o tem, contribuindo, dessa forma, na manutenção da sobrevivência dessa última parcela da população.

Nessa perspectiva, não somente os que ainda têm emprego devem desenvolver atividades sociais por meio do trabalho voluntário, mas também aqueles que buscam o primeiro emprego e aqueles que, mesmo desempregados, ainda se consideram aptos a se reinserirem no mercado de trabalho, buscando adequar-se ao perfil da empregabilidade.

Se o desenvolvimento de atividades voluntárias, de natureza social, tem sido posto subliminarmente ou explicitamente aos funcionários das empresas, como condição para manutenção do emprego e princípio a ser incorporado e desenvolvido por aqueles que buscam atender ao perfil da empregabilidade, pode-se dizer que o trabalho voluntário desenvolvido por força da RSE é involuntário, forçado, coercitivo, obrigatório.

Desse modo, pode-se afirmar que existe o trabalho que é de fato voluntário. Trata-se daquele que parte de iniciativa espontânea do indivíduo, como uma atividade de caráter solidário, humanitário ou de caridade. Porém, existe também o trabalho que se intitula voluntário, mas que, na verdade, é forçado. E o trabalho voluntário ligado à RSE enquadra-se nesta situação.

O "trabalho voluntário forçado" compõe a força de trabalho quando possibilita o aumento do lucro da empresa, mesmo parecendo ao trabalhador estar fora da jornada e das atribuições do trabalho. O 
"trabalho voluntário forçado" compõe também as relações sociais de trabalho na sociedade capitalista, no âmbito da superestrutura, como auxiliar na manutenção e reprodução desse modo produtivo, no que diz respeito especificamente à sua contribuição para atenuar os efeitos do desemprego estrutural e quando também contribui para substituir parte do papel do Estado no desenvolvimento de atividades de natureza social, já que o próprio capitalismo exauriu sua capacidade de financiamento (do Estado).

As considerações de Marx são bastante elucidativas, ao afirmar que "um negro é um negro. Apenas dentro de determinadas condições ele se torna um escravo. Uma máquina de fiar algodão é uma máquina de fiar algodão. Ela se transforma em capital apenas em condições determinadas" (s/d, p. 69). Parafraseando o filósofo alemão, poder-se-ia dizer: o trabalho voluntário é trabalho voluntário. Apenas em determinadas condições ele aumenta a possibilidade da realização monetária da mais-valia na circulação, diante da concorrência.

\section{Considerações finais}

No decorrer dessas reflexões enfocamos as "novas" modalidades de intervenção do setor produtivo privado na educação escolar, evidenciando os discursos, diretrizes e práticas do empresariado, mediante a implementação das políticas de "responsabilidade social empresarial" e de "açóes voluntárias" preconizadas pelo setor. Nesse contexto, o quadro social das duas últimas décadas, sob a moldura da reforma do Estado e da ascensão das políticas neoliberais, garantiu, com vigor, a proliferação desses processos, engendrando impactos estruturais, sobretudo por meio de dois flancos:

a) garantia da lucratividade e produtividade empresarial pela intensificação da exploração do trabalhador por meio do trabalho voluntário;

b) acirramento da instauração da lógica mercantil em diversos espaços da esfera social, como a escola.

Tais aspectos suscitam novos questionamentos e reafirmam nossas certezas sobre a necessidade do restabelecimento da esfera social e de uma escola de fato pública, plural, democrática, com qualidade 
Educação e responsabilidade empresarial: "novas" modalidades de atuação...

socialmente referenciada. É preciso também que a escola se constitua como espaço, no qual, mediante sua gestão, currículo, conteúdos e metodologias, haja questionamentos da naturalização dos diferentes mecanismos de poder, desigualdades e injustiças que tangenciam o tempo presente. Como Sacristán (2000), também acreditamos que interessa saber o que governa o presente para intervirmos nesse governo. Assim, é importante resgatar o presente real para que as imagens que elaboremos sirvam para nos refletir. "Isto é o aspecto importante do trabalho intelectual: pretender alcançar a capacidade reflexiva de ver onde estamos e para onde nos leva o que estamos fazendo, para não cair no escapismo e distrair-se numa prospectiva que não é possível no mundo indeterminado" (p. 39).

Perante uma conjuntura na qual, paradoxalmente, ocorre a precarização das relações de trabalho e a intensificação das exigências de um novo perfil de trabalhador em suas características cognitivas, comportamentais e plásticas - decorrentes das inovaçôes derivadas da dinâmica gestorial, da microeletrônica, da automação e da robótica -, a educação escolar é posta como uma aliada das empresas para responder aos desafios de qualificação do trabalhador no processo de mundialização do capital. Neste contexto, um importante desafio para os profissionais da educação se instaura: captar as nuanças contidas nas proposições do empresariado para a escola, no processo de estabilização do seu poder econômico e político, e apreender as mediações pautadas na cidadania, construídas historicamente pela dinâmica escolar, como possibilidades de fortalecer o ethos da educação pública.

Recebido em julho de 2009 e aprovado em agosto de 2009.

\section{Nota}

1. Para maiores detalhamentos das proposições do empresariado para a educação pública, ver Silva (2001).

Referências

AFONSO, A.J. Estado, globalização e políticas educacionais: elementos para uma agenda de investigação. Revista Brasileira de Educação, Rio de Janeiro, n. 22, jan./abr. 2003. 
APPLE, M. Ideologia e currículo. São Paulo: Brasiliense, 1982.

BEGHIN, N. A filantropia empresarial: nem caridade, nem direito. São Paulo: Cortez, 2005.

BERNARDO, J. Estado: a silenciosa multiplicação do poder. São Paulo: Escrituras, 1998.

BOURDIEU, P. Coisas ditas. São Paulo: Brasiliense, 1990.

BRASIL. Manifesto dos Pioneiros da Educação. 1932. (mimeo).

BRASIL. Ministério da Administração e Reforma do Estado. Plano Diretor da Reforma do Aparelho de Estado. Brasília, DF, 1995.

BUCCI, E. A solidariedade que não teme aparecer. In: BuCCI, E.; KeHL, M.R. Videologias. São Paulo: Boitempo, 2004. p. 180-187.

CASTRO, M.C. Um espaço de discussão: compartilhamento e aprendizado. In: Perez, C.; Junqueira, L.P. (Org.). Voluntariado e a gestão de políticas sociais. São Paulo: Futura, 2002, p. 70-83.

FOUCAULT, M. A ordem do discurso. 4 ed. São Paulo: Loyola, 1998.

GRAYSON, D.; HODGES, A. Compromisso social e gestão empresarial. São Paulo: Publifolha, 2002.

INSTITUTO DE EDUCAÇÃO E INOVAÇÃO (IEDI). Mudar para competir - A nova relação entre competitividade e educação; estratégias empresarias. [S.1.]: IEDI, [1992?].

INSITUTO HERBERT LEVY. Ensino fundamental e competitividade empresarial: uma proposta para ação do governo. São Paulo: IHL, 1996.

LESSA, R. Marketing social melhora a imagem e aumenta o lucro. In: O FUTURO da Comunicação; relatório da Gazeta Mercantil. São Paulo, 2002. p. 22.

MARX, K. Trabalho assalariado e capital. In: MARX, K.; Engels, F. Obras escolhidas. São Paulo: Alfa-Omega, [1982?]. v.1., p. 52-82.

MARX, K. O capital. 15 ed. Rio de Janeiro: Bertrand Brasil, 1996. Livro 1, v. 1. 
Educação e responsabilidade empresarial: "novas" modalidades de atuação...

MCINTOSH, M. et al. Cidadania corporativa: estratégias bem-sucedidas para empresas responsáveis. Rio de Janeiro: Qualitymark, 2001. MÉSZÁROS, I. A educação para além do capital. São Paulo: Boitempo, 2002.

MINARELLI, J.A. Empregabilidade: o caminho das pedras. São Paulo: Gente, 1995.

PEREZ, C.; JUNQUEIRA, L.P. (Org.). Voluntariado e a gestão de politicas sociais. São Paulo: Futura, 2002.

SACRISTÁN, J.G. A educação que temos, a educação que queremos. In: Imbernón, F. A educação no século XXI: o desafio do futuro imediato. Porto Alegre: ARTMED, 2000. p. 37-61.

SILVA, M.V. Empresa e escola: do discurso da sedução a uma relação complexa. 2001. 355f. Tese (Doutorado em Educação) - Universidade Estadual de Campinas, Campinas.

SILVA FILHO, H.P. O empresariado e a educação. In: FerretTi, J.C. et al (Org.). Novas tecnologias, trabalho e educação: um debate multidisciplinar. 3 ed. Petrópolis: Vozes, 1996. p. 87-92.

SOUZA, M.I. Os empresários e a educação: IPES e a questão educacional após 1964. São Paulo: Cortez, 1981.

TRAGTENBERG, M. Administração, poder e ideologia. São Paulo: Moraes, 1980. 